\section{Simultaneous Multiple Locations of Hydatid Cyst: Extrapleural, Intrapulmonary and Subcutaneous}

Sir,

Hydatid cyst is a parasitic disease most commonly caused by E.Granulosis. Though it is most frequently seen in liver (50-60\%) and lung (15-27\%), it can also occur in heart, kidney $(2-3 \%)$, spleen $(0,9-8 \%)$, orbit $(1 \%)$, pancreas, breast, skin and soft tissue $(2-3 \%) .{ }^{1}$ The hydatid cyst gradually grows; and symptoms and signs are seen according to the tolerance of the organ it is located in. Clinical findings can vary depending on the size of the cyst, localisation and the condition of the cyst.2-4 Also, an allergic reaction to cyst rupture may occur independently of the location. Mortality is seen in about $4 \%$ of hydatid cyst disease. 5

A 39-year male patient with chronic renal failure, poliomyelitis sequelae, and history of hydatid cyst operation was admitted to surgery clinic with complaints of back swelling. An abscess formation was found on ultrasonography. Thoracic computed tomography confirmed paravertebral abscess leading to lytic changes in the right lower ribs (Figure 1). The patient underwent operation by the general surgeon. Degenerative cysts and vesicles were evacuated from the patient's paravertebral subcutaneous lesions under local anesthesia. Emergency thoracotomy was performed under general anesthesia for extrapleural and intrapulmonary lesions. Cystectomy and capitonnage were carried out in the lung (Figure 2). The chest tube was removed on the seventh day of operation. Albendazole (10 $\mathrm{mg} / \mathrm{Kg} / \mathrm{day})$ was started and the patient was discharged.
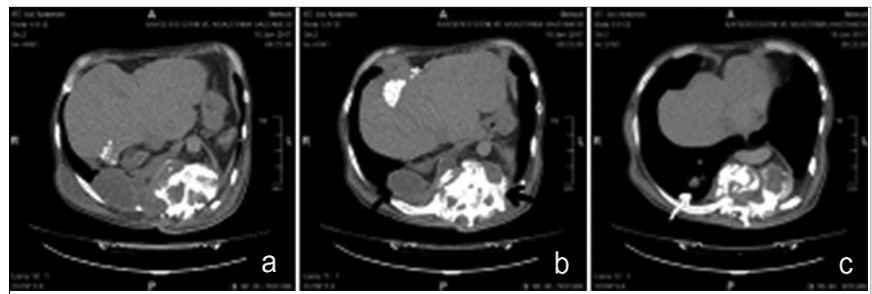

Figure 1: Preoperative CT images of hydatid cyst (a: subcutaneous, b: extrapleural, c: intrapulmonary) in the patient.

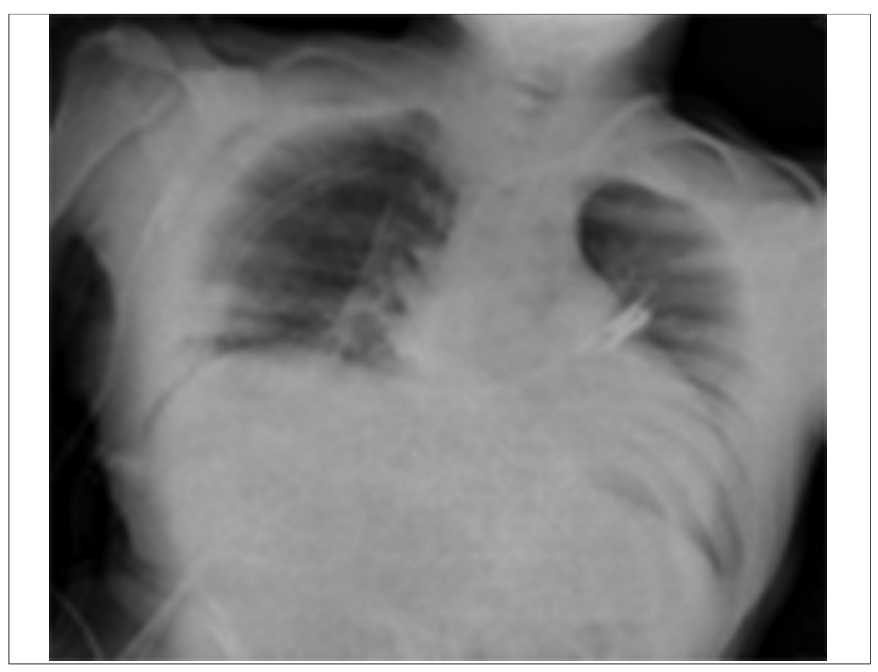

Figure 2: Postoperative X-ray graphy.

It is important to remember that hydatid cyst is able to infest all the parts of the body, and it is widespread in our country. If hydatid cyst disease is suspected, adequate clinical information should be given to the radiology unit and it should be considered in the differential diagnosis.

\section{REFERENCES}

1. Celebi S, Basaranoglu M, Karaaslan H, Demir A. A splenic hydatid cyst case presented with lumbar pain. Intern Med 2006; 45:1023-4.

2. Bal N, Kocer NE, Arpaci R, Ezer A, Kayaselcuk F. Uncommon locations of hydatid cyst. Saudi Med J 2008; 29:1004-8.

3. Yuksel M, Demirpolat G, Sever A, Bakaris S, Bulbuloglu E, Elmas N. Hydatid disease involving some rare locations in the body pictorial essay. Korean J Radiol 2007; 8:531-40.

4. Oruç M, Sahin A, Meteroglu F, Onat S, Durkan A, Ülkü R, et al. Comparison of demographical characteristics, prognostic factors, and surgical outcomes in children and adult patients with pulmonary hydatid cyst. Eurasian J Pulmonol 2017; 19: 166-9.

5. Mono P, Scantz PM. Echinococcosis a review. Int J Infect Disease 2009; 13:125-33.

Mehmet Akif Tezcan and Ibrahim Ethem Ozsoy

Department of Thoracic Surgery, Kayseri Training and Research Hospital, Kayseri, Turkey

Correspondence: Dr. Mehmet Akif Tezcan, Department of Thoracic Surgery, Kayseri Training and Research Hospital, Kayseri, Turkey

E-mail: mehmetakiftercan@gmail.com

Received: April 12, 2018; Accepted: August 10, 2018 